\title{
A Novel Porous Diamond - Titanium Biomaterial: Structure, Microstructure, Physico-Mechanical Properties and Biocompatibility
}

\author{
ZULMIRA A.S. GUIMARÃES ${ }^{1}$, RENATO A. DAMATTA ${ }^{2}$, RENAN \\ S. GUIMARÃES ${ }^{1}$ and MARCELLO FILGUEIRA ${ }^{1}$ \\ ${ }^{1}$ Laboratório de Materiais Avançados, Centro de Ciência e Tecnologia, Universidade Estadual do Norte Fluminense \\ Darcy Ribeiro, Avenida Alberto Lamego, 2000, Campos dos Goytacazes, 28013-602 Rio de Janeiro, RJ, Brazil \\ ${ }^{2}$ Laboratório de Biologia Celular e Tecidual, Centro de Biociências e Biotecnologia, Universidade Estadual do Norte \\ Fluminense Darcy Ribeiro, Avenida Alberto Lamego, 2000, Campos dos Goytacazes, 28013-602 Rio de Janeiro, RJ, Brazil
}

Manuscript received on November 25, 2016; accepted for publication on June 7, 2017

\begin{abstract}
With the aim of introducing permanent prostheses with main properties equivalent to cortical human bone, Ti-diamond composites were processed through powder metallurgy. Grade 1 titanium and mixtures of $\mathrm{Ti}$ powder with $2 \%, 5 \%$ and $10 \mathrm{wt} \%$ diamond were compacted at $100 \mathrm{MPa}$, and then sintered at $1250^{\circ} \mathrm{C} / 2 \mathrm{hr} / 10^{-}$ ${ }^{6} \mathrm{mbar}$. Sintered samples were studied in the point of view of their microstructures, structures, yield strength and elastic modulus. The results showed that the best addition of diamonds was $2 \mathrm{wt} \%$, which led to a uniform porosity, yield strength of 370MPa and elastic modulus of $13.9 \mathrm{GPa}$. Samples of Ti and Ti-2\% diamond were subjected to in vitro cytotoxicity test, using cultures of VERO cells, and it resulted in a biocompatible and nontoxic composite material.
\end{abstract}

Key words: biomaterials, titanium, diamond, sintering, characterization, biocompatibility.

\section{INTRODUCTION}

Titanium (Ti) and their alloys comprise the most appropriate metallic materials developed for biomedical applications, based on excellent biocompatibility, low elastic modulus, and density, high yield strength and corrosion, considered to be superior when compared to other metallic materials used for the same purpose (stainless steel and cobalt-chromium alloys) (Mohammed et al. 2014, Niinomi 2010).

Titanium alloys are considered more suitable for the fabrication of implants in general. Nevertheless,

Correspondence to: Marcello Filgueira

E-mail: marcello.filgueira@pq.cnpq.br they demonstrate sensitive biomechanical mismatch to possess elastic modulus (E) higher than the human bone. Due to the difference in stiffness, the load of the implant is not properly transferred to the bone, creating shear stresses at the bone-implant interface, damaging the bone and causing loosening of the implant, which may result in premature failures and reduced life of the prosthesis. This is called stress Shielding (Yuhua et al. 2014, Mas-Moruno et al. 2013).

The reduction of the shear force and elasticity of the metallic material can be obtained by making it porous, which reduces the damage to the tissue adjacent to the implant, enabling bone-implant 
interconnection and consequently increasing bone fixation and longer lifetime (Oh 2003). In this sense, the powder metallurgy process (PM) is advantageous, as it enables control of porosity, uniformity in the product and reduces the manufacturing costs (Froes and Pickens 1984).

As a disadvantage, Ti presents a high coefficient of friction, which results in low wear resistance. Titanium alloys having high coefficient of friction, can cause wear of the material resulting in pain and loosening of the implants due to osteolysis (Ching et al. 2014). Accordingly, various surface modification techniques have been proposed to reduce the coefficient of friction (Souza et al. 2015, Mohseni et al. 2014).

The diamond was presented as a possible coating material for orthopedic implants because of their high hardness and low friction coefficient, giving it high wear resistance. Diamond has chemical stability and biocompatibility ideal for use in biomedical materials (Grill 2003, Tang et al. 1995).

Studies show that diamond films on titanium implants alloys exhibit high adhesion and low coefficient of friction, increase wear resistance and allow the implant osteogenesis due to the high chemical stability and biocompatibility, linked to high resistance to bacterial colonization and bioactivity at molecular level (Ivanova et al. 2011, Yang et al. 2009).

In this study, the powder metallurgy route is used to process a new biomaterial, Ti-diamond, where the later is distributed into the Ti matrix. This composite showed a suitable in vitro biocompatibility.

\section{MATERIALS AND METHODS}

\section{PROCESSING}

Titanium powder with mean particle size of $40 \mu \mathrm{m}$ (from Merck), and diamond powder with mean crystal size of $0.25 \mu \mathrm{m}$ (by Element Six), were manually mixed in the compositions of $2 \%, 5 \%$ and $10 \mathrm{wt} \%$ of diamond. Pure Ti powder was used as matter of comparison.

The mixtures were compacted using uniaxial pressing, using a cylindrical steel die at a pressure of $100 \mathrm{MPa}$. The compacted green bodies with dimensions of $5 \mathrm{~mm}$ diameter and $4 \mathrm{~mm}$ height were sintered at $1250{ }^{\circ} \mathrm{C}$ for 2 hours under a vacuum of $10^{-6} \mathrm{mbar}$, according to conditions recommended when using pure commercially $\mathrm{Ti}$ as a biomaterial for spinal cortical bone implant (Doi et al. 2009).

\section{CHARACTERIZATION}

\section{Density and porosity}

Density ( $\rho)$ measurements were performed by the geometrical method of mass and volume. Therefore, porosity was also obtained.

\section{Microstructural analyses}

The samples without metallographic treatment were analyzed by Scanning Electron Microscopy (SEM), secondary (SE) and backscattered electron (BSE) modes in the microscope Superscan/SS50050 by Shimadzu. After metallographic preparation the samples were observed again in SEM, which were subjected to chemical analysis by Energy Dispersive Spectroscopy (EDS). It was analyzed: the distribution of diamonds in the titanium matrix, morphology and interconnectivity of pores, and the interactions between titanium and diamonds.

\section{Structural Analyses}

It was performed by $\mathrm{x}$-ray diffraction (XRD) to verify the possible formation of Ti-C (diamonds) compounds, and oxidation of Ti. Analyses were performed using a Shimadzu 7000 diffractometer, using $\mathrm{CuK} \alpha$ radiation, and a nickel filter. Operating parameters: $35 \mathrm{kV}, 40 \mathrm{~mA}, 2 \theta$ ranging from 25 to $90^{\circ}$, with step of $0.02^{\circ} / \mathrm{sec}$. 


\section{Yield strength and elastic modulus}

Compression tests were conducted in a universal testing machine Instron Model 5582, at a crosshead speed of $1 \mathrm{~mm} / \mathrm{min}$. Yield strength and elastic modulus were recorded. After the characterizations, the composite which showed the best global results, along with pure Ti were subjected to in vitro cytotoxicity test.

In vitro CYTOTOXICITY TEST

\section{Maintenance of cells in culture}

VERO cells (cell line established from kidney cells of African green monkey, Cercopithecus aethiops), recommended by ISO 10993-5 standard for in vitro cytotoxicity test, were maintained in Dulbecco's modified Eagle's medium (DMEM-1152, Sigma) supplemented with 5\% fetal bovine serum (FBS, Nutricell), in atmosphere containing 5\% CO2 at $37{ }^{\circ} \mathrm{C}$. The medium exchanges were performed whenever the acidification occurred.

The cells were plated at a density of $8 \times 10^{4}$ cells $/ \mathrm{ml}$, in the presence of samples of $\mathrm{Ti}$ and $\mathrm{Ti}$ diamond; in the absence of these samples (negative control for citotoxicity); and pre-treated with $1 \%$ Triton X100 (positive control for citotoxicity), allowing cells to attach for $24 \mathrm{~h}$ before the treatments.

\section{Cell viability}

Cell viability was determined by quantification of lactate dehydrogenase (HDL), intracellular enzyme released to the culture medium when the cell plasma membrane is damaged, indicative of cell death.

The measurement of HDL was performed using the commercial kit from Doles brand (Doles Reagents, Goiânia/Brazil). The absorbance was measured at $420 \mathrm{~nm}$ in a microplate reader (Versa Max/Molecular Devices).

The results obtained on the content of HDL were statistically analyzed by ANOVA.

\section{Morphological analyses}

The morphology and cell adhesion to the composite were studied by SEM Superscan/SS500-50 Shimadzu.

After 24 hours, samples were removed from the plate, fixed in $2.5 \%$ glutaraldehyde, $0.1 \mathrm{M}$. cacodylate buffer ( $\mathrm{pH} 7.2$ ), post-fixed with $1 \%$ osmium tetroxide (Sigma), dehydrated in increasing concentrations of ethanol dried to critical-point (Baltec CPD- 030 equipment), and sputtered with platinum (SCD- 050 Sputter Baltec).

\section{RESULTS AND DISCUSSION}

\section{DISTRIBUTION OF DIAMONDS IN THE COMPOSITE}

It was possible to observe in relation to pure $\mathrm{Ti}$ (Fig. 1a) the characteristic diamond agglomerates along the surfaces of the unpolished composites (Fig. 1bd), which increased the surface roughness. It was possible to identify the presence of diamonds in these clusters (darker parts) in the vicinity where Ti suffers apparent morphological changes, with rough texture (Fig. 1f to $h$ ).

The particles of diamond powders agglomerated at some points of the sample, which characterizes the non-uniform distribution which can be attributed to the mixing process. One possible solution proposed for future work is processing the mixture in a high-energy ball mill, under argon atmosphere, considering the high reactivity of $\mathrm{Ti}$ with oxygen.

EDS analysis of polished samples confirmed that the darker regions (identified by SEM-BSE) correspond, in fact, to diamond (Fig. 2). Points 1, 2 and 3 in Figure 2 are regarded to carbon, titanium and carbon, and pure titanium, respectively, observed in the corresponding spectra, in point 2 it is possible the formation of some titanium carbide.

Figure 3 highlights the contact region between Diamond and Titanium, and features the apparent morphological change in the interface assigned to 

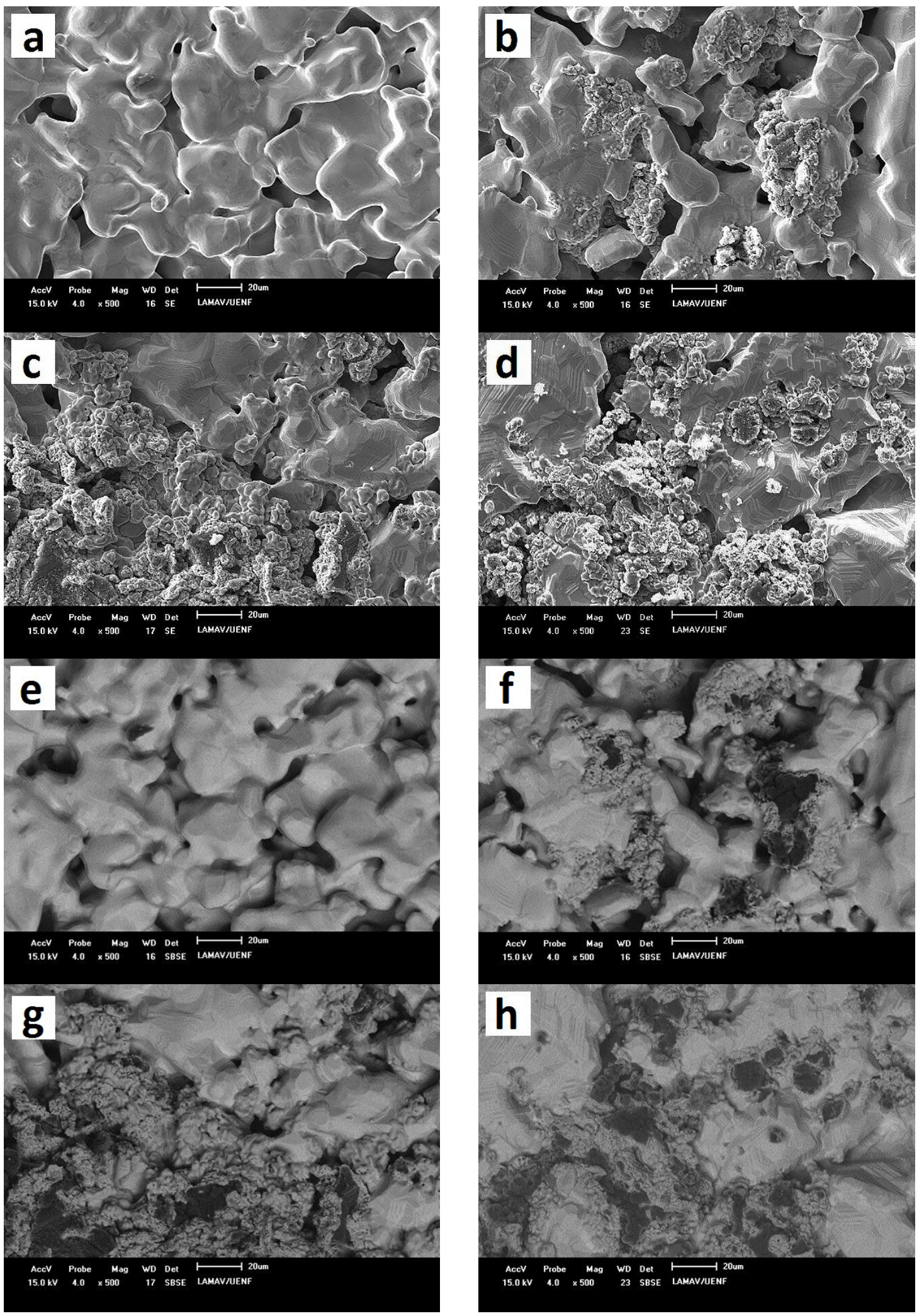

Figure 1 - SEM micrographs of the top surface of the sintered samples without metallographic treatment. SE (a-Ti, b-Ti2D, c-Ti5D, d-Ti10D) and BSE (e-Ti, f-Ti2D, g-Ti5D, and h-Ti10D). Magnification 500x. 



Figure 2 - Micrograph of the polished surface of the composite Ti-5\% diamond with marking points analyzed by EDS (a). Magnification 300x. The corresponding spectra represent the chemical composition of points 1 (b), 2 (c) and 3 (d).



Figure 3 - Interface between Ti (light area) and Diamond (dark region) in 3000x magnification. The arrows indicate the roughness near the diamond formed by the presence of TiC.
TABLE I

Density and porosity of samples.

\begin{tabular}{ccccc}
\hline Samples & $\begin{array}{c}\text { Theoretical } \\
\boldsymbol{\rho}\left(\mathbf{g} / \mathbf{c m}^{\mathbf{3}}\right)\end{array}$ & $\begin{array}{c}\text { Real } \boldsymbol{\rho} \\
\mathbf{( g / \mathbf { c m } ^ { 3 } )}\end{array}$ & $\begin{array}{c}\text { Relative } \boldsymbol{\rho} \\
\mathbf{( \% )}\end{array}$ & $\begin{array}{c}\text { Porosity } \\
\mathbf{( \% )}\end{array}$ \\
\hline Pure Ti & 4.51 & $3.50 \pm 0.2$ & $77.70 \pm 0.2$ & $22.0 \pm 0.7 \mathrm{~d}$ \\
Ti-2D & 4.48 & $3.17 \pm 0.3$ & $70.70 \pm 0.3$ & $29.0 \pm 0.3 \mathrm{~b}$ \\
Ti-5D & 4.45 & $3.27 \pm 0.6$ & $73.60 \pm 0.6$ & $26.0 \pm 0.3 \mathrm{c}$ \\
Ti-10D & 4.38 & $3.05 \pm 0.5$ & $69.70 \pm 0.5$ & $30.0 \pm 0.3 \mathrm{a}$
\end{tabular}

Means followed by different letters are statistically different from each other at $1 \%$ probability level $(p<0.01)$ by Tukey's test.

the fronts of formation of titanium carbide (TiC). It is still visible after polishing - see arrows, and a cluster of diamond particles in the sample - darker region. XRD results prove this TiC formation, as presented ahead. 


\section{DENSITY}

Table I shows the density of the sintered samples. The gradual decrease in density of the composites with additions of diamonds was expected, since the density of diamond $\left(3.51 \mathrm{~g} / \mathrm{cm}^{3}\right)$ is lower than that of titanium $\left(4.51 \mathrm{~g} / \mathrm{cm}^{3}\right)$. In this case, the change in this tendency for Ti-5D samples can be attributed to a higher diamond agglomeration in the mixture, in which Ti rich regions sintered better than diamond rich regions.

\section{POROSITY}

The average porosity values of the samples obtained in this study are shown in Table I. The statistical analyses were performed using the Tukey's test.

Studies by Oh et al. $(2002,2003)$ indicate that the porosity can control the elastic modulus, and have an influence on the yield stress, so that such properties tend to decrease as the porosity increases. The same studies show that when the porosity is approximately $30 \%$, the modulus of elasticity of titanium is very close to that of human cortical bone. Thus, the porosity values presented in Table I are satisfactory.

The pores have irregular shape and a few small pores presented spherical morphology, and

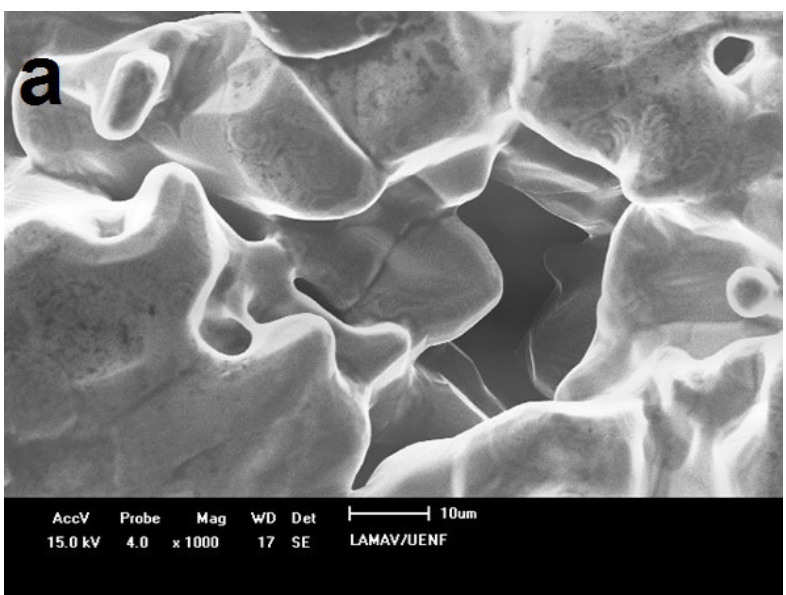

they propagate into the material, as shown in figure 4a. The arrangement of the pores on the surface of the material indicates the possibility of pores' interconnectivity (Fig. 4b). These open pores, and, interconnected channels maintains vascular space necessary for bone mineralization (Hulbert et al. 1970, Li et al. 2001).

Research indicates that the size and volume of pores exerts direct influence on bone growth According to Hulbert et al. (1970), the minimum pore size for the ingrowth of mineralized bone is around $100 \mu \mathrm{m}$. Other authors argue that it occurs in the range from 100 to $350 \mu \mathrm{m}$ (Shin et al. 2004). Later, Takenomoto et al. (2005) stated that $30 \mu \mathrm{m}$ pores allow bone growth. In this paper, overall porosity is around $30 \mu \mathrm{m}$.

\section{STRUCTURAL ANALYSIS BY XRD}

According to XRD results presented in Fig. 5, only Ti $\alpha$ hexagonal phase is found, as expected. In Ti-2D sample it was observed the appearance of peaks of $\mathrm{TiC}$, which is the product of the reaction of $\mathrm{Ti}$ with the carbon atoms of the diamond during sintering. The sample Ti-5D experienced an increase in the intensity of the peaks of both $\mathrm{TiC}$ and diamond, when compared to Ti-2D, this is attributed to the increasing percentage of diamonds in the composite. The sample of Ti-10D, the TiC

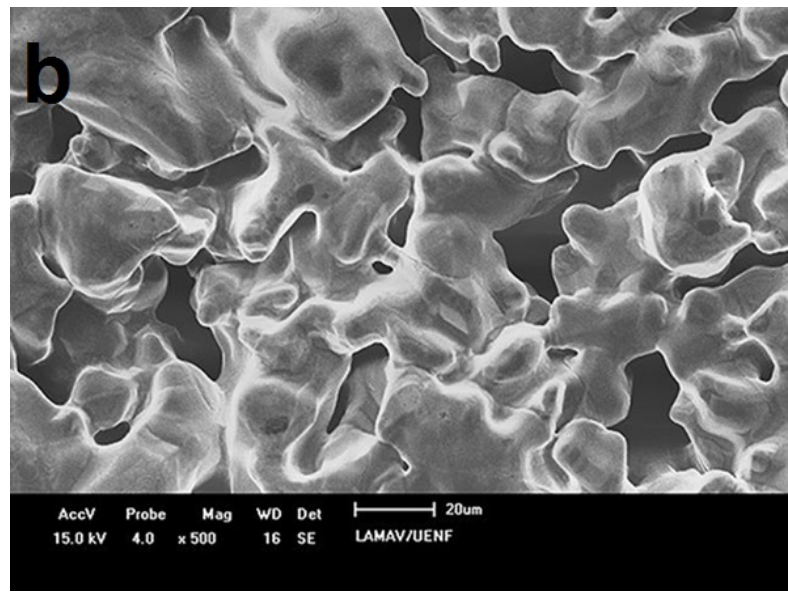

Figure 4 - Micrograph evidencing a pore on the surface of Ti at 1000x magnification (a). Distribution of pores on the surface of the material (b). 


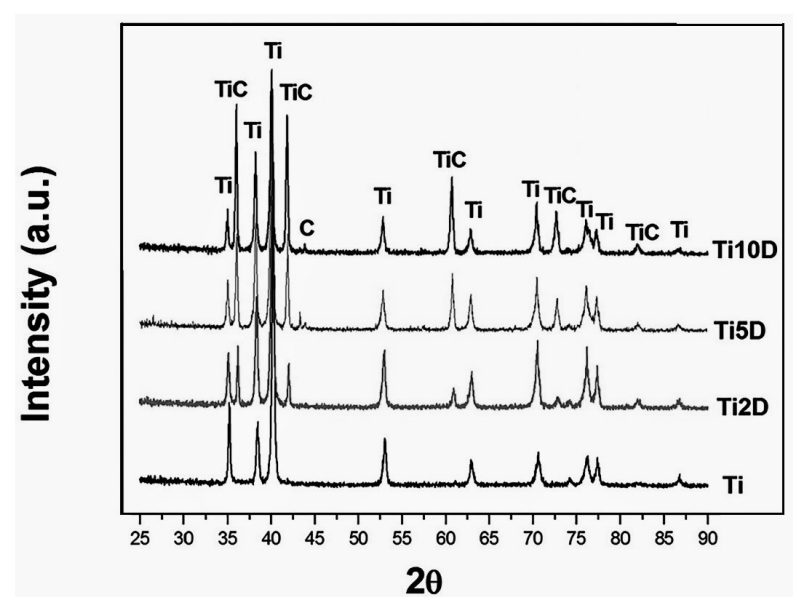

Figure 5 - XRD patterns of the samples.

peaks are at higher intensities when compared to other composites, which is to be expected since for larger amounts of diamond (carbon atoms), larger amounts of $\mathrm{TiC}$ are also formed.

It is worth saying that no other carbon allotropic or amorphous form was observed. This is an evidence that the employed high vacuum sintering of $10^{-6} \mathrm{mbar}$ protected the diamonds to transform to other carbonaceous forms.

SEM and EDS analysis revealed that the TiC is a porous coating on the particles of diamond, at the interfaces with Ti. Concerning the use of TiC in biomaterials, it was stated that $\mathrm{TiC} / \mathrm{Ti}$ coating on substrates of TiNi (titanium-nickel alloy) significantly increase the corrosion resistance, and acts as a protective barrier against the release of $\mathrm{Ni}$ ions, which is harmful to human health (Takemoto et al. 2005).

Zhu et al. (2012) have studied the abrasion resistance of $\mathrm{TiC}$ CVD coated $\mathrm{Ti}$, in order to use in implants. The results indicate a high abrasion resistance promoted by the $\mathrm{TiC}$ film.

\section{COMPRESSION TEST}

The elastic moduli and yield stress obtained in this study are presented in Table II. Statistical analyses were performed using Tukey's test.

Values are close to that of human cortical bone (10 to $30 \mathrm{GPa}$ ) (Niinomi 1998), which means
TABLE II

Results obtained from compression tests.

\begin{tabular}{|c|c|c|}
\hline Samples & $\begin{array}{c}\mathrm{E} \\
(\mathrm{GPa})\end{array}$ & $\begin{array}{c}\text { Yield stress } \\
\text { (MPa) }\end{array}$ \\
\hline $\mathrm{Ti}$ & $9.1 \pm 0.7 \mathrm{c}$ & $* 390 \pm 8 \mathrm{a}$ \\
\hline Ti-2D & $* 13.9 \pm 1.1 \mathrm{~b}$ & $* 370 \pm 13 \mathrm{a}$ \\
\hline Ti-5D & $* 12.5 \pm 0.9 \mathrm{~b}$ & $300 \pm 17 b$ \\
\hline Ti-10D & $16.9 \pm 0.9 \mathrm{a}$ & $240 \pm 21 \mathrm{c}$ \\
\hline
\end{tabular}

* Means followed by the same letter are not statistically different from each other at the $5 \%$ probability level $(\mathrm{p}<0.05)$, by Tukey's test.

that the proposed reduction in elastic modulus by controlling porosity was found to be effective for the processed materials.

It is observed a gain in stiffness by adding diamond because the ceramic particles reduce the ductility of the material, and promote second phase hardening.

It is observed that the presence of diamond reduces the yield strength of the samples. This can be explained by: (1) poor distribution of diamond particles, where segregation acts as stress concentrator and cracks nucleating source, and (2) the possible low adhesion between diamond/ titanium due to the formation of $\mathrm{TiC}$ coatings on diamonds, which weakens the diamond composites, because this coating is porous (see Fig. 3), reducing the interfacial adhesion.

According to ISO (1999) and ASTM (2006) standards, the minimum yield strength of pure Ti grade 1, for application as biomaterial for orthopedic implants is $170 \mathrm{MPa}$, and maximum elastic modulus 116GPa. Therefore, all produced composites meet these requirements.

Despite of the achieved results, it is important to inform that the thickness of human cortical bone (external portion) is thinner than that of cancellous bone, where this later occupies mostly the core part. Therefore, the implant material must present similar elastic modulus (E) when compared to that 


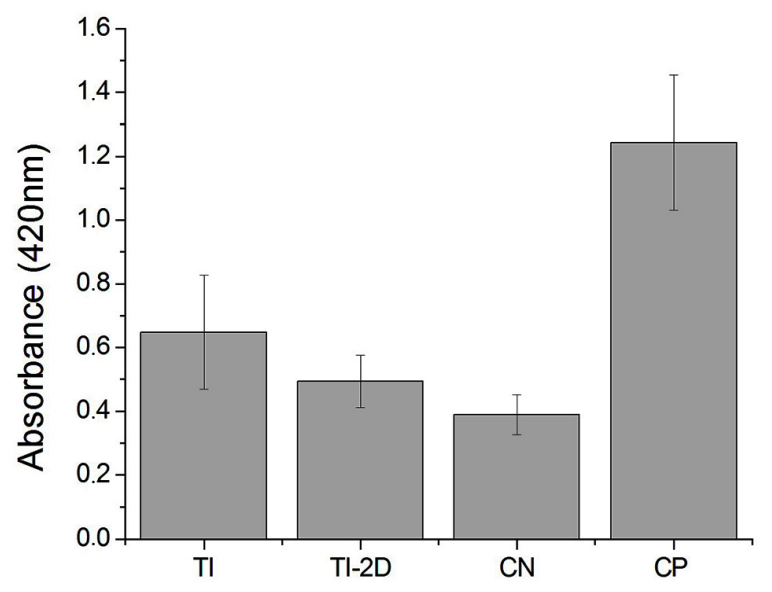

Figure 6 - HDL results.

of cancellous bone, rather than cortical one. The elastic modulus of the processed diamond composites must be reduced even more, aiming at an approximation to the value of the cancellous bone. Increase in porosity may be the key to solve this problem.

\section{CELL VIABILITY}

The positive cytotoxicity control (CP) demonstrated high cells' lethality, as expected, which can be observed by the high LDH index in the medium - see Fig. 6. The negative control (CN) presented a considerable decrease of LDH when compared to $\mathrm{CP}$, indicating few dead cells in the medium. There was also a decrease in the LDH content in Ti-2D and Ti, when compared to CP. According to the statistical analysis (by ANOVA) there was no significant difference in cell viability among $\mathrm{Ti}$ and Ti-2D with respect to $\mathrm{CN}$, indicating that both $\mathrm{Ti}$ and Ti-2D materials did not show cytotoxicity in VERO cells.

The statistical analysis (ANOVA) showed no significant difference between treatments with $\mathrm{Ti}$, Ti-2D and the negative control, indicating that both materials tested showed no cytotoxicity in VERO cells (Table III).
TABLE III

ANOVA statistical analyses for the samples subjected to the HDL test.

\begin{tabular}{cc}
\hline ANOVA: Means Results Determination \\
\hline $\mathrm{Ti}$ & $* 0.64813 \mathrm{~b}$ \\
$\mathrm{Ti}-2 \mathrm{D}$ & $* 0.49373 \mathrm{~b}$ \\
$\mathrm{CN}$ & $* 0.38910 \mathrm{~b}$ \\
$\mathrm{CP}$ & $1.24380 \mathrm{a}$ \\
\hline
\end{tabular}

*Means followed by the same letter are not statistically different. Tukey test at $5 \%$ probability level was applied.

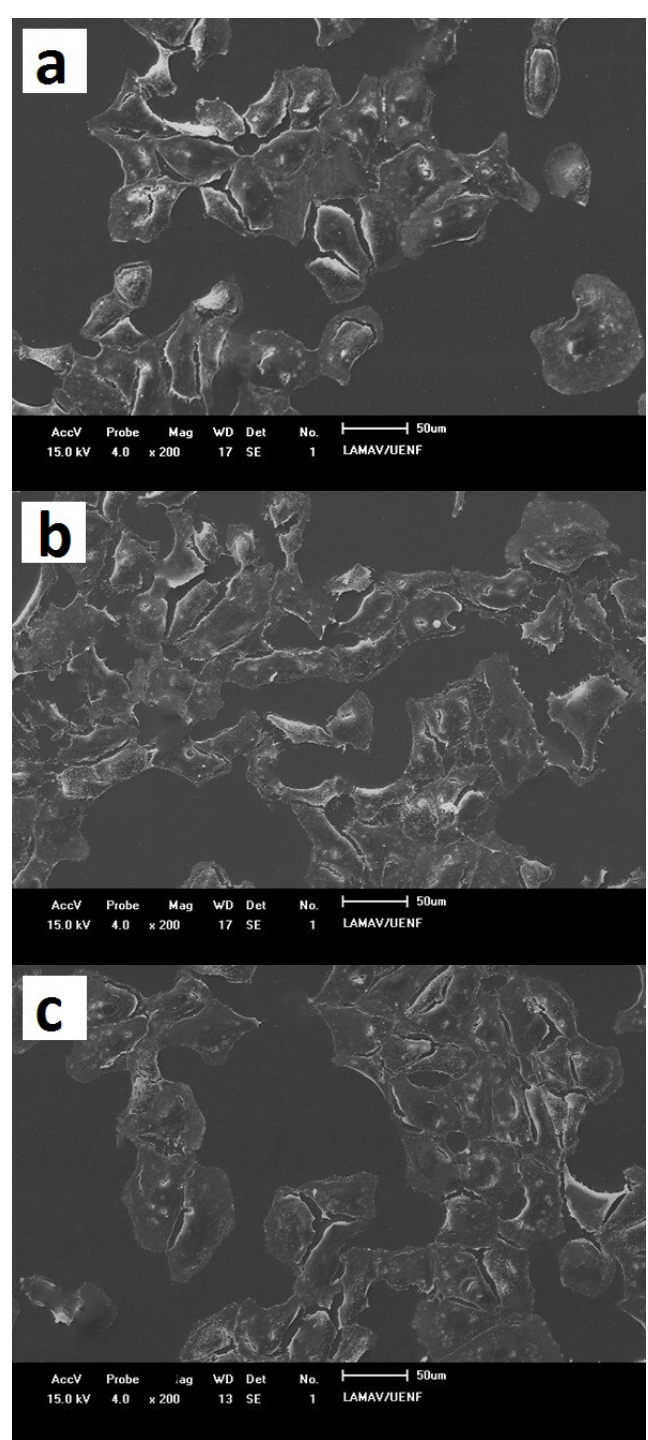

Figure 7 - Electron micrographs of Vero cells after 24 hours culture. Control group (a), in medium with Ti (b) and Ti-2D (c), observed in 200x magnification. 



Figure 8 - Samples Ti (a) and Ti-2D (b) 24 hours after inoculation of Vero cells in 200x magnification. Arrows indicate cells on the surface of the materials.
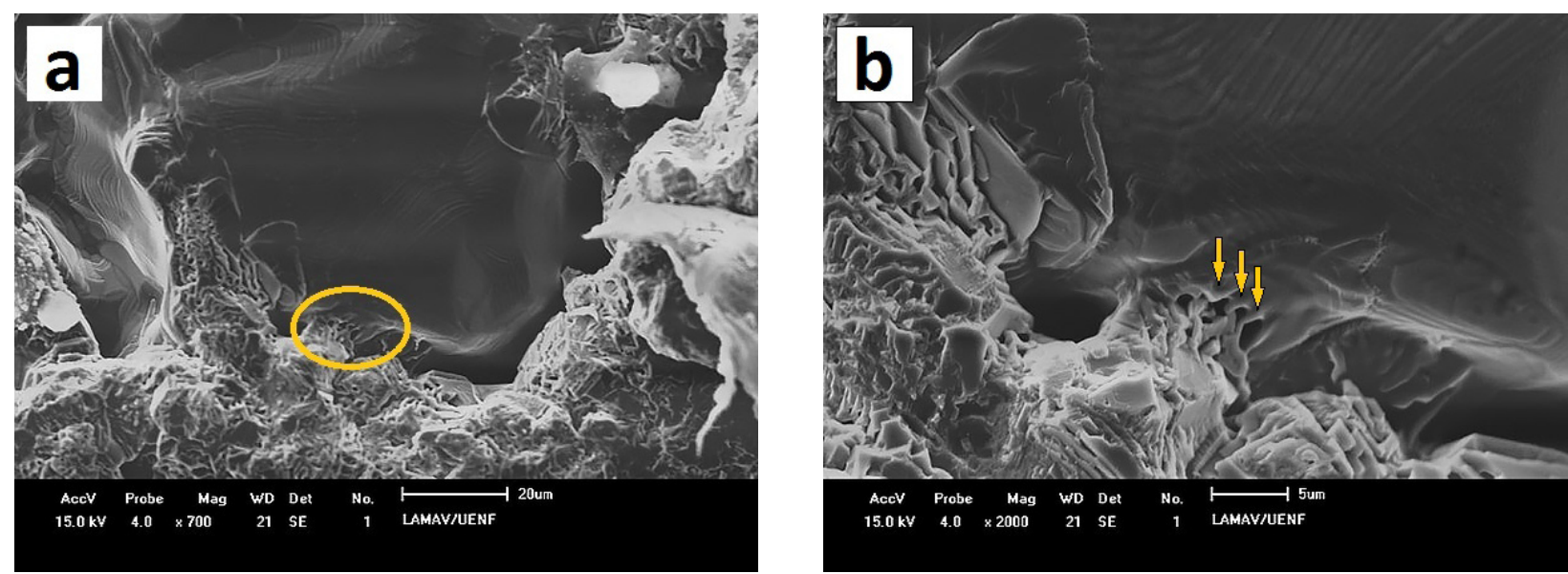

Figure 9 - Cell adhered on titanium surface (a). Circular region marked in Figure a at higher magnification (b), whose arrows point to possible cytoplasmic extensions towards the surface of Ti.

\section{CELL MORPHOLOGY}

Cells grown on coverslips in Ti and Ti-2D samples, and in their absence (control), showed similar morphological features as well as adhesion and spreading, confirming that the presence of $\mathrm{Ti}$ as much as the composite Ti- 2D did not change cell morphology (Fig. 7).

Figure 8 shows cells with initial adhesion process on Ti and Ti-2D samples' surfaces (smooth dark gray surfaces), indicated by arrows, evidencing good interaction with these substrates (samples). This fact may be associated with surface topography which presented high roughness, indicating a possible relationship between cell proliferation, microstructure and substrate type.

Possible evidence of plasma membrane projections toward the surface of the material are seen in Fig. 9 - depicted by arrows, possibly characterizing mechanical cell adhesion on the surface of the material.

\section{CONCLUSIONS}

From the results obtained in this exploratory study, it can be concluded that: The densification and porosity obtained for the composites were satisfactory, in which the average pore size and 
morphology are favorable to osseointegration. Diamonds increased porosity because it does not sinter under the used sintering conditions. Diamonds' agglomerations were observed, what explains well the porosity increase when diamond is added. Naturally, when hard ceramic particles are added to a soft metal matrix such as Ti, the composite suffers a gain in stiffness $(\mathrm{E})$ - it can be solved by increasing the porosity. The yield stress of the material decreases with the presence of diamond, which can be attributed to poor distribution of diamonds in the composites, as well as the low interfacial adhesion Diamond / Ti due to the TiC formation. Amongst the processed diamond composites, the composite Ti-2D showed better results of physical and mechanical properties for this purpose. The processed composites can not be used as a cortical bone implant, because their elastic moduli are high, when the cancellous bone stiffness is considered. The biological tests allow us to state that the composite Ti-2D demonstrated biocompatibility, with cell adhesion and proliferation, better than pure Ti.

\section{ACKNOWLEDGMENTS}

Authors would like to express their gratitude to Fundação Carlos Chagas Filho de Amparo à Pesquisa do Estado do Rio de Janeiro (FAPERJ) and Conselho Nacional de Desenvolvimento Científico e Tecnológico (CNPq), and to Element Six Company for granting the nano-sized diamond powder.

\section{REFERENCES}

ASTM. 2006. F67-06, Standard Specification for Unalloyed Titanium, for Surgical Implant Applications (UNS R50250, UNS R50400, UNS R50550, UNS R50700), ASTM International, West Conshohocken.

CHING HA, CHOUDHURY D, NINE MJ AND OSMAN NAA. 2014. Effects of surface coating on reducing friction and wear of orthopaedic implants. Sci Technol Adv Mat 15: 144.
DOI K, MATSUSHITA T AND KOKUBO T. 2009. Mechanical properties of porous titanium and its alloys fabricated by powder sintering for medical use. In: Plansee Seminar 17, Reutte, Proceedings of $17^{\text {th }}$ International Plansee Seminar, Ed. Plansee Group, Reutte, Austria, p. 1084.

FROES FH AND PICKENS JR. 1984. Powder metallurgy of light metals alloys for demanding applications. JOM 36: 14-27.

GRILL A. 2003. Diamond-like carbon as biocompatible materials. Diam Relat Mater 12: 166-170.

HULBERT SF, YOUNG FA, MATHEWS RS, KLAWITTER JJ, TALBERT CD AND STELLING FH. 1970. Potential of ceramic materials as permanently implantable skeletal prostheses. J Biomed Mater Res 4: 433-456.

ISO - INTERNATIONAL ORGANIZATION FOR STANDARDIZATION. 1999. ISO 5832-2 Implants for surgery - Metallic materials Part 2: Unalloyed titanium. Geneva.

IVANOVA L. 2011. Nanocrystalline diamond containing hydrogels and coatings for acceleration of osteogenesis. Diam Relat Mater 20: 165-169.

LI YH, RONG LJ AND LI YY. 2001. Pore characteristics of porous NiTi alloy fabricated by combustion synthesis. J Alloys Compd 325: 259-262.

MAS-MORUNO C, ESPANOL M, MONTUFAR EB, MESTRES G, APARICIO C, GIL FJ AND GINEBRA MP. 2013. Bioactive ceramic and metallic surfaces for bone engineering. In: Taubert A et al. (Eds), Biomaterials Surface Science, Wiley-VCH, Germany, p. 337-374.

MOHAMMED MT, KHAN ZA AND SIDDIQUEE AN. 2014. Beta titanium alloys: the lowest elastic modulus for biomedical applications: a review. Int J Chem Mol Nucl Mater 8: 726-731.

MOHSENI E, ZALNEZHAD E, SARHAN AAD AND BUSHROA ARA. 2014. Study on surface modification of A17075-T6 alloy against fretting fatigue phenomenon. Adv Mater Sci Eng 20: 1-17.

NIINOMI M. 1998. Mechanical properties of biomedical titanium alloys. Mater Sci Eng A 234: 231-236.

NIINOMI M. 2010. Metals for Biomedical Devices. CRC Press, New York, $357 \mathrm{p}$.

OH IH, NOMURA N AND HANADA S. 2002. Microstrutures and mechanical properties of porous titanium prepared by powder sintering. Mater Trans 43: 443-446.

OH IH, NOMURA N, MASAHASHI N AND HANADA S. 2003. Mechanical Properties of porous titanium compacts prepared by powder sintering. Scr Mater 49: 1197-1202.

SHIN M, YOSHIMOTO H AND VACANTI JP. 2004. In vivo bone tissue engineering using mesenchymal stem cells on a novel electrospun nanofibrous scaffold. J Tissue Eng 10: 33-41.

SOUZA JCM, TAJIRI HA, MORSCH CS, BUCIUMEANU M, MATHEW MT, SILVA FS AND HENRIQUES B. 
2015. Tribocorrosion behavior of Ti6Al4V coated with a bio-absorbable polymer for biomedical applications. J Bio Tribo- Corr 1: 1-6.

TAKEMOTO M, FUJIBAYASHI S, NEO M, SUZUKI J, KOKUBO T AND NAKAMURA T. 2005. Mechanical properties and osteoconductivity of porous bioactive titanium. Biomaterials 26: 6014-6023.

TANG L, TSAI C, GERBERICH WW, KRUCKEBERG L AND KANIA DR. 1995. Biocompatibility of chemicalvapor deposited diamond. Biomaterials 16: 483-488.
YANG L, SHELDON BW AND WEBSTER TJ. 2009. The impact of diamond nanocrystallinity on osteoblast functions. Biomaterials 30: 3458-3465.

YUHUA L, CHAO Y, HAIDONG Z, SHENGGUAN Q, XIAOQIANG L AND YUANYUAN L. 2014. New developments of Ti-based alloys for biomedical applications. Materials 7: 1709-1800.

ZHU Y, WANG W, JIA X, AKASAKA T, LIAO S AND WATARI F. 2012. Deposition of TiC film on titanium for abrasion resistant implant material by ion-enhanced triode plasma CVD. Appl Surf Sci 262: 156-158. 